\title{
Práticas de reescrita no ensino do gênero resenha
}

\section{The Process of Rewriting In The Teaching of Genre Reviews}

\author{
Júlio Araújo* \\ Universidade Federal do Ceará \\ Fortaleza - Ceará / Brasil \\ Marcilene Gaspar Barros** \\ Universidade Federal do Ceará \\ Fortaleza - Ceará / Brasil \\ Elinaldo Soares Silva*** \\ Universidade Federal do Ceará \\ Fortaleza - Ceará / Brasil
}

\begin{abstract}
RESUMO: A escrita de gêneros acadêmicos exige perícia e reflexão e deve se configurar como um processo constante de reescrita, marcado por muitos ajustes linguístico-textuais. Acreditando que a vivência desse processo pode ser ensinada, o objetivo deste artigo é refletir sobre a reescrita do gênero resenha por estudantes do curso de Letras da Universidade Federal do Ceará (UFC). A base teórica desse exercício de análise procede da perspectiva de reescrita proposta por Fabre-Cols (2002) e da teoria de gêneros de Swales (1984; 1990). À luz desses autores, analisamos as mudanças efetuadas em resenhas acadêmicas (re) escritas por esses estudantes no decorrer da disciplina "Leitura e Produção de Textos Acadêmicos" (LPTA). Os resultados revelam que muitas das alterações realizadas pelos estudantes relacionam-se diretamente aos movimentos retóricos característicos do gênero, apropriados mais significativamente por eles durante a reescrita orientada em sala de aula.
\end{abstract}

PALAVRAS-CHAVE: Gênero textual resenha; Reescrita; Movimentos retóricos.

ABSTRACT: The writing of academic genres demands proficiency and reflection and must be viewed as a continuous rewriting process marked by many linguistic-textual adjustments. Believing in the possibility of teaching

\footnotetext{
*araujo@ufc.br

**marcilenegbarros@yahoo.com.br

***elinaldo23@hotmail.com
} 
this process to the students, we discuss in this paper the rewriting of the genre 'review' by students of the undergraduate course of Languages and Literatures from the Federal University of Ceara - Brazil. Through Fabre-Cols' theoretical propositions about the rewriting of texts and Swales' theory of genre, we analyzed the changes that the students made to the genre for a subject called "Reading and Writing of Academic Texts". The data show that all the changes are directly related to the genre's characteristic rhetorical moves, which the students were able to internalize during the oriented rewriting activity in the classroom. KEYWORDS: Review; Genre; Rewriting; Rhetorical moves.

\section{Introdução}

As pesquisas acerca da revisão de textos a partir da década de 1980, com os estudos de Hayes e Flower, até os dias atuais, têm demonstrado a preocupação dos teóricos em compreender essa etapa do processo de escrita. Inicialmente, dentro de um modelo mais amplo, Flower e Hayes (1981) dividiram a etapa da revisão em dois subprocessos, designados de avaliação e correção. Posteriormente, foram criados novos modelos, que consolidaram a revisão como um processo cognitivo complexo, de natureza recursiva e interativa, podendo ocorrer em qualquer momento da produção e incidir sobre qualquer parte do texto. Um modelo responsável por dar sequência a muitos desses estudos é o de Hayes et al. (1987). Desenvolvido a partir de protocolos verbais, sintetiza processos cognitivos, como: definição da tarefa de revisão, avaliação para detecção e diagnóstico de problemas, seleção de estratégias de resolução desses problemas e concretização das modificações do texto ou do plano.

Um aspecto rediscutido por Hayes (2004) envolvendo o modelo de Hayes et al. (1987) é a definição da tarefa, a qual fornece um espaço para o controle metacognitivo durante o processo de revisão, além de variar entre os escritores e de ser modificada dinamicamente como produto da revisão. Outro ponto destacado pelo teórico (2006) diz respeito ao papel de uma ampla classe de estruturas explicativas, comumente chamadas de frameworks, que são concebidas como representações que nos ajudam a pensar sobre os processos complexos. Assinala o estudioso que uma estrutura simples pode consistir em nada mais do que uma breve lista de elementos ou características. Com base nessa discussão, Hayes (2006) cita modelos que auxiliam a pensar em situaçôes complexas, tais como: modelos que podem ajudar na memória, por exemplo, aquele utilizado por jornalistas, que se encontra na memória de cada um quando criam ou editam uma notícia (quem, onde, quando, 
o quê e por que); modelos que podem oferecer linguagem comum como o de Hayes e Flower (1980), cuja estrutura tem proporcionado linguagem comum para discutir processos cognitivos na escrita; modelos que podem facilitar a aquisição e organização do conhecimento, permitindo perceber relações entre os itens de conhecimento já armazenados na memória e, assim, proporcionar uma oportunidade de reorganizar esse conhecimento; modelos que podem desencadear previsões empíricas como o de revisão proposto por Hayes et al. (1987).

Hayes (2006) chama atenção para a utilidade desses modelos, uma vez que permitem organizar o pensamento, pois fornecem linguagem comum para a comunicação e fornecem pistas para a memória, além de promover a aquisição de novos conhecimentos, já que destacam semelhanças, desencadeiam previsões e fornecem base para programas de pesquisas.

De forma geral, os referidos estudos ampliaram-se na tentativa de compreender estratégias utilizadas pelos escritores na revisão e reescrita de seus textos. Diferentemente da abordagem finalista, centrada apenas no produto, estudos que exploram atividades de produção escrita do ponto de vista do processo, nos quais os alunos são submetidos a diferentes modalidades de revisão, evidenciam um ganho de qualidade ao texto no que diz respeito à identificação e correção de problemas locais e globais nos textos (CARVALHO, 2002; SOARES, 2003). Isso acontece, mediante as mudanças operacionalizadas pelos escritores provenientes do processo de revisão: a supressão, o acréscimo (ou adição), a substituição e o deslocamento (FABRE-COLS, 2002; BARROS; SOARES, 2013).

Diante do exposto, considerando que a escrita de um gênero acadêmico não é uma tarefa fácil, sobretudo quando se trata de escritores iniciantes, pois a literatura tem mostrado que os sujeitos preocupamse demasiadamente com aspectos puramente formais ao revisarem e reescreverem seus textos, buscamos, neste trabalho, analisar as mudanças efetuadas em textos reescritos por graduandos do segundo semestre do curso de Letras, verificando em que medida as mudanças efetuadas se relacionam aos movimentos retóricos característicos do gênero resenha. Acreditamos que, se as mudanças operacionalizadas nos textos a partir das operações de adição, supressão, substituição e deslocamento ocorrerem também em função dos movimentos retóricos do gênero em questão, constituirão dados relevantes para a escrita de gêneros acadêmicos, pois podem sinalizar para a preocupação do escritor com o gênero em si que se materializa em uma 
determinada estrutura para cumprir um propósito comunicativo, entre outros aspectos.

Consideramos, portanto, duas questôes pertinentes neste trabalho: primeira, a preocupação dos sujeitos centrada em aspectos formais, questão já ratificada em trabalhos realizados anteriormente (CARVALHO, 2002; SOARES, 2003); segunda, o foco do trabalho desenvolvido pelo professor, especialmente auxiliado por modelos que preveem estratégias retóricas usadas no gênero em estudo, que podem redirecionar o olhar dos sujeitos, mesmo que estes ainda não estejam familiarizados com a escrita de gêneros acadêmicos.

Quanto à estrutura, este artigo está organizado da seguinte forma: inicialmente, abordamos o ensino da escrita com ênfase nos gêneros textuais; em seguida, discorremos acerca dos fundamentos teóricos que embasam o estudo da revisão (FLOWER e HAYES, 1981; HAYES, 2004) e as mudanças operacionalizadas nos textos (FABRE-COLS, 2002); depois, apresentamos a análise dos dados e a discussão dos resultados; por fim, tecemos nossas considerações finais.

\section{O ensino da escrita com ênfase nos gêneros textuais}

Ensinar linguagem sob a perspectiva dos gêneros é trabalhar "com a compreensão de seu funcionamento na sociedade e na sua relação com os indivíduos situados naquela cultura e suas instituiçôes" (MARCUSCHI, 2005 , p.10). A perspectiva de ensino da língua baseada no conceito de gênero está pautada numa concepção de língua como interação, o que equivale a afirmar que compreende a escrita como prática social e reconhece que todo texto (oral ou escrito) realiza propósitos comunicativos em uma situação específica. Assim, a noção de gênero permite descrever a relação entre o propósito social do texto e sua estrutura linguística (BHATIA, 2004). Inscritos em uma perspectiva didática da psicologia da linguagem, Schneuwly e Dolz (1995) afiançam que o gênero funciona como um modelo comum, que determina um horizonte de expectativa para os membros de uma comunidade confrontados às mesmas práticas de linguagem, o que permite trazê-lo para os cenários pedagógicos do ensino do texto em sala de aula.

Nesse sentido, Santos (2004) salienta que, se entendermos que o processo de escrita envolve a mobilização tanto de conhecimentos sobre a língua quanto sobre o contexto no qual é produzida, sobre o seu propósito e 
habilidades no uso desta modalidade da língua, então, o desenvolvimento da escrita ocorre através da promoção do potencial do aluno e de fornecimento de input pelo professor. Por esse motivo, na abordagem do ensino da escrita a partir dos gêneros deve-se estar atento não apenas para a realidade do texto em uso (seus porquês e para quês), mas também para os modos de recepção e de circulação (o modo de funcionamento textual).

Nessa perspectiva, os Parâmetros Curriculares Nacionais de Língua Portuguesa (BRASIL, 1997) preconizam a necessidade de tornar mais real e efetivo o trabalho do aluno na escola como produtor de textos, de forma que o ensino possa oportunizar a esse aluno situações didáticas propícias a múltiplas formas de atuação social, encarando e enxergando a atividade de escrita não como um fim (geralmente de avaliação), mas como um dos caminhos possíveis para a expressão daquilo que ele tem a dizer em determinado momento.

Assim, no ensino, o aluno precisa ser estimulado a analisar os diferentes propósitos comunicativos que informam os modelos de regularidades na linguagem. Considerando que diferentes gêneros requerem diferentes tipos de conhecimentos e diferentes conjuntos de habilidades, o ensino da produção textual não pode ser o mesmo para todo e qualquer gênero a ser estudado. Tal postura é defendida por Schneuwly e Dolz ao enfatizarem a necessidade de um trabalho sistemático, com vistas à aprendizagem da escrita. Para eles,

\footnotetext{
(...) o ensino que visa ao domínio textual requer uma intervenção ativa do professor e o desenvolvimento de uma didática específica. Constituindo-se o aprendizado da escrita uma aprendizagem social e os gêneros construções sócio-históricas, sua apropriação e domínio se efetuam sempre no interior das interaçôes entre os membros de uma dada sociedade. Ou seja, a aprendizagem da escrita não é algo que se dá de modo espontâneo, mas se constrói através de uma intervenção didática sistemática e planejada. (SCHNEUWLY e DOLZ, 1995, p.15)
}

Compreende-se, portanto, a preocupação de pesquisadores que têm defendido um ensino sistemático da produção escrita de diferentes gêneros, desde o início da escolaridade (BONINI, 2002; ARAÚJO, 2007; ARAÚJO; SANTOS, 2012). Não se trata apenas de permitir o acesso, o manuseio ou a produção de diferentes tipos de textos, mas efetivar um ensino sistemático, explicitando-se "o conhecimento implícito do gênero" (SCHNEUWLY e 
DOLZ, 1995, p.35). Essa perspectiva implica rever as propostas dos anos de 1980, assumindo um trabalho de didatização que não foi explicitado nos documentos oficiais (BIASI-RODRIGUES, 2002).

Conforme Santos (2004), ao mesmo tempo em que a escola reflete o mundo extraescolar, ela difere discursivamente desse mundo. Isso implica dizer que o conhecimento escolar é constituído por generalizações e requer muitas vezes o uso de metalinguagens. A afirmação da autora não defende o ensino da metalinguagem e da gramática normativa, mas argumenta que o acesso a certos domínios e discursos requer a sua explicitação. Por isso, faz-se necessário trazer para a escola explicitamente os "como" e os "porquês" da linguagem. Apesar disso, afigura-se relevante lembrar, como bem recomenda Snyder, que

quando a linguagem é vista como fixa e guiada por regras prescritivas, então a gramática formal é ensinada através de treinos e exercícios. Contudo, quando a linguagem é vista como dinâmica, mais facilmente aprendida por meio do uso, a gramática é ensinada como parte do processo de escrita, no momento da necessidade. ${ }^{1}$ (SNYDER, 2008, p.159)

Na visão de Schneuwly e Dolz (1995), cabe à escola decidir sobre o trabalho de escrita a ser desenvolvido com gêneros textuais de forma a atingir, pelo menos, dois objetivos: o primeiro deles está atrelado ao fato de conhecer e compreender melhor o gênero para produzi-lo na escola e, principalmente, fora dela; o segundo diz respeito a desenvolver habilidades de escrita que, além do gênero foco da escrita em uma situação específica de aprendizagem, possam contribuir para a aprendizagem de outros gêneros, sejam eles mais próximos do gênero em estudo, sejam mais distantes.

Esse trabalho didático deve procurar alocar os alunos, ao mesmo tempo, em uma situação o mais perto possível de verdadeiras situações de comunicação e que tenham um sentido para eles (DIEB, 2013), mas também deixar claro que eles estão inseridos numa dinâmica de ensino-aprendizagem dentro de uma instituição que tem por objetivo fazer-aprender. Isso implica não desconsiderar a noção de "modelo", mas agora em outra perspectiva, diferente da tratada nos currículos tradicionais e na proposta dos anos de 1980.

\footnotetext{
${ }^{1}$ Nossa tradução livre de: "When language is seen as fixed and guided by prescriptive rules, then formal grammar is taught through drills and exercises. But when language is seen as dynamic, best learned through use, grammar is taught as part of the writing process, at the point of need." (SNYDER, 2008, p.159).
} 
Não se trata de modelos de bons textos, como modelos a serem imitados, nem textos previamente elaborados para serem trabalhados na escola. Antes, pressupõe que, para aprender a escrever um determinado gênero textual, o aluno deve ser posto em contato com um repertório textual do gênero que está aprendendo e que lhe sirva de referência. Em relação a esse aspecto, Dolz et al. salientam a importância de

que o aluno não imite os textos escolares, mas que produza textos com referência a situaçōes de comunicação bem definidas, precisas e reais: uma verdadeira explicação de um fenômeno desconhecido; uma verdadeira descrição de uma catedral para um Guia Turístico; uma verdadeira receita culinária que possa ser feita em casa. (DOLZ et al., 2004, p.70)

Embora existam diferenças entre as alternativas propostas para o ensino-aprendizagem da escrita a partir dos gêneros, um aspecto perpassa todas elas: a de que aprender a escrever é uma prática social que se constrói com a ajuda de uma intervenção sistemática e planejada. Ou seja, a aprendizagem da escrita não é algo que ocorre de forma espontânea; é necessário, entre outros aspectos, ensinar os alunos a serem revisores e editores de seus próprios textos.

\section{Revisão e reescrita de textos}

Dirigir o olhar ao processo de produção do texto, quando até então se centrava no produto, foi uma das grandes contribuições dos estudos de abordagem cognitiva de Flower e Hayes (1981). A concepção de escrita como atividade que envolve processos psicológicos, ou seja, operaçôes mentais que são acionadas pelo sujeito no momento em que escreve um texto, fez com que estudiosos repensassem tanto questôes teóricas quanto práticas, levando-os a investigar o ensino da escrita em sala de aula. Como importante etapa desse processo, a revisão de texto tem ocupado um espaço considerável, trazendo contribuiçôes relevantes à escrita.

Vista dessa perspectiva cognitiva, considera-se a revisão como um processo, no qual o sujeito identifica e corrige problemas no texto, de forma que isso lhe permite promover mudanças e, assim, alterar o escrito. Tais alterações podem estar relacionadas diretamente às normas linguísticas, ao conteúdo abordado, à audiência, entre outros aspectos (GONÇALVES, 1992). Por outro lado, há uma visão de que a revisão ainda está muito voltada 
para aspectos da superfície do texto, como substituir e suprimir palavras, reduzir frases longas, colocar frases na voz ativa, eliminar as duplas negativas, por exemplo (SERAFINI, 1992; ANTUNES, 2003).

Durante a revisão, o sujeito mobiliza diversos conhecimentos guardados na memória, tais como conhecimentos aprendidos na escola, conhecimentos adquiridos em situaçóes diversas ou mesmo construídos em experiências anteriores de escrita, que exercem influência na reelaboração do texto por ocasião do processo de revisão. Assim, tais conhecimentos são atualizados, modificados, em função das escolhas e atitudes do sujeito diante dos problemas detectados. Portanto, cabe àquele que escreve decidir sobre o que fazer perante tais problemas. É bem verdade que as estratégias variam de escritor para escritor e envolvem, entre outras: ignorar o problema, adiar a correção, promover modificaçõos no texto etc.

Uma das propostas que podem iluminar a prática do ensino de reescrita resulta do trabalho de Fabre-Cols (2002), que relaciona os estudos da crítica genética com os estudos sobre reescrita de textos produzidos por escolares franceses. Em seu trabalho, a autora percebeu que, para os sujeitos de sua pesquisa, o ato de escrever não depende unicamente de saberes linguísticos uma vez que, conectados a esses saberes, estão a capacidade de projetar a escrita, o desejo e idoneidade para negociar as escolhas de natureza textual. Na perspectiva da didática das línguas, as marcas de reescrita deixadas no texto não se circunscrevem apenas aos saberes linguísticos, mas podem ser interpretadas como marcas enunciativas que caracterizam o exercício de reescrita.

Essa autora apresenta quatro tipos de operações linguísticas que são utilizadas pelos escritores na revisão/reescrita do texto, quais sejam:

1. Adição: ocorre quando há o acréscimo de elementos, podendo ser um acento, um sinal de pontuação, uma palavra, um sintagma, uma ou várias frases etc.;

2. Supressão: consiste no apagamento de elementos e, como a adição, também pode ser aplicada sobre diversas unidades linguísticas (acento, sílabas, palavras, frases);

3. Substituição: nesta operação linguística ocorre a supressão de um elemento que é substituído por um novo elemento. Isso pode ocorrer com palavras, sintagmas ou sobre conjuntos generalizados;

4. Deslocamento: permite que um elemento (ou vários) se desloque para outra parte do texto, alterando a ordem e promovendo uma nova configuração. 
Segundo a tese defendida neste artigo, acreditamos que, ao se envolverem no processo de reescrita de seus textos, os estudantes participantes de nosso estudo promovem essas operações com o objetivo de se aproximarem dos movimentos retóricos que caracterizam a escrita do gênero resenha.

\section{Resenha acadêmica: considerações sobre o gênero, os produtores e o cenário pedagógico}

Assim como a escola, a universidade também é uma agência de letramento e nela são praticados muitos gêneros que organizam as necessidades enunciativas dos sujeitos que atuam nos cenários acadêmicos. Nesse sentido, estudantes recém-ingressos nos cursos superiores tendem a apresentar dificuldades para compreender os contratos de linguagem que regem a produção e o consumo de gêneros nessa esfera de atividade. Entre os gêneros mais praticados está a resenha, objeto de reflexão neste artigo.

Motta-Roth e Hendges (2010) argumentam que compete à resenha fornecer uma opinião crítica sobre um determinado livro, de forma que, tanto o resenhador - que descreve e avalia uma obra a partir do conhecimento adquirido ao longo do tempo sobre o assunto em questão - quanto o leitor têm objetivos convergentes, já que o autor da resenha fornece uma visão crítica e o leitor busca tal informação.

Sobre a estrutura retórica da resenha, Motta-Roth e Hendges (2010) destacam quatro etapas, nas quais o resenhador realiza os seguintes movimentos retóricos: 1) apresentar, 2) descrever, 3) avaliar e 4) (não) recomendar o livro. Segundo as autoras, tais ações, geralmente, aparecem nessa ordem, mas podem variar em extensão. Tanto a noção de movimentos retóricos quanto esse modelo, porém, procedem dos estudos de Swales (1984; 1990). Considerando que os gêneros são artefatos semióticos que obedecem a padrões mínimos que recorrem em seus exemplares, Swales (1984) procurou estudar se havia rotinas de escrita que pudessem caracterizar a prática da produção de artigo científico. Assim, ao estudar um corpus constituído de vários exemplares desse gênero praticados por pesquisadores de diversas áreas (ciências "puras", ciências sociais, biologia e medicina), o estudioso percebeu que em todas as áreas estudadas o gênero artigo acadêmico apresentava regularidades que sinalizavam para algo que o caracterizava como tal. Desse exercício, Swales (1984) elaborou uma proposta metodológica para análise de gêneros, a qual foi designada de Create A Research Space (CARS). 
Esse modelo, que passou por diversas reformulações, tem sido bastante aplicado e replicado por outros autores. Foi por essa proposta que as teorias de gêneros chegaram à linguística brasileira. $\mathrm{O}$ modelo foi utilizado por Motta-Roth (1995), Araújo (1996) para o estudo de resenhas acadêmicas e por Biasi-Rodrigues (1998) para o estudo de resumos de dissertações de mestrado. A partir dessas pesquisas, muitas outras seguiram na aplicação bem sucedida dessa abordagem metodológica para análise de gêneros.

No caso do trabalho de Motta-Roth (1995), após a análise de sessenta resenhas de livros em inglês nas áreas de química, economia e linguística, a aplicação do modelo CARS revelou a recorrência de determinadas ações, conforme observamos no esquema a seguir.

\section{APRESENTAR O LIVRO}

$\begin{array}{ll}\text { Passo } 1 & \text { informar o tópicico geral do livro } \\ \text { Passo } 2 & \text { definir o público-âvo } \\ \text { Passo } 3 & \text { dar referências sobre o autor } \\ \text { Passo } 4 & \text { fazer generalizaçós } \\ \text { Passo } 5 & \text { inserir o livro nả disciplina }\end{array}$

e/ou

e/ou

\section{DESCREVER O LIVRO}

$\begin{array}{lll}\text { Passo } 6 & \text { dar uma visão geral da organização do livro } & \text { e/ou } \\ \text { Passo } 7 & \text { estabelecer o topico de cada capítulo } & \text { e/ou }\end{array}$

Passo 8 citar material extratextual

\section{AVALIAR PARTES DO LIVRO}

Passo 9 realçar pontos específicos

4. (NÃO) RECOMENDAR O LIVRO

Passo 10A desqualificar/recomendar olivro e/oụ e/ou Passo 10B recomendar o livro apesar das falhas indicadas

Descrição esquemática das estratégias retóricas usadas no gênero resenha (Motta-Roth, 1995, p.143)

Posteriormente, em uma perspectiva didática, Motta-Roth e Hendges chamam a atenção para as especificidades de resenhas em áreas diversas, como, por exemplo, química, economia e linguística, uma vez que cada disciplina faz uso de estratégias diferenciadas para promover a comunicação entre seus pares. Assim, esclarecem que enquanto "resenhadores em química tendem a adotar uma visão mais ampla do livro sem avaliaçôes exaustivas, [...] economistas e linguistas tendem a produzir uma argumentação mais extensa e elaborada [...]”. (MOTTA-ROTH e HENDGES, 2010, p.45) 
Levando-se em consideração as discussões aqui apresentadas, a partir dos estudos de Flower e Hayes (1981) sobre revisão, da tipologia de FabreCols (2002) acerca da classificação das operações efetuadas pelos sujeitos na reescrita do texto, e da descrição esquemática das estratégias retóricas usadas no gênero resenha de Motta-Roth (1995), selecionamos oito textos, produzidos por dois graduandos do segundo semestre do curso de Letras da Universidade Federal do Ceará, na disciplina de Leitura e Produção de Textos Acadêmicos (LPTA), período de fevereiro a junho de 2012, para verificarmos se há relação entre as mudanças identificadas na reescrita e os movimentos retóricos da resenha.

Os textos que compõem o corpus deste estudo foram coletados em duas turmas da disciplina de LPTA, ministrada pelo primeiro autor deste artigo, em colaboração com uma equipe de quatro monitores (bolsistas de iniciação à docência) e dois mestrandos de Linguística, que, na época, desenvolveram estágio de docência sob a orientação do referido professor. Em virtude da dinâmica de produção, revisão e reescrita dos textos, e da natureza de nosso estudo, fizemos o seguinte recorte: trabalhamos com oito versóes dos textos escritos, sendo quatro textos do sujeito A (turma 01A) e quatro textos do sujeito B (turma 02A). Nosso corpus constitui-se, portanto, de oito textos do gênero resenha, conforme apresentamos no quadro a seguir.

QUADRO 1

Quantitativo dos textos analisados

\begin{tabular}{|l|l|l|l|l|}
\hline Sujeito A (SA) & Escrita da resenha 1 & Reescrita da resenha 1 & Escrita da resenha 2 & Reescrita da resenha 2 \\
\hline Sujeito B (SB) & Escrita da resenha 1 & Reescrita da resenha 1 & Escrita da resenha 2 & Reescrita da resenha 2 \\
\hline
\end{tabular}

Considerando que os textos analisados foram escritos em duas situações distintas, esclarecemos que a versão inicial do texto 1 consistiu na escrita de um texto elaborado em sala de aula, com tempo restrito. Para isso, o professor solicitou na aula anterior que os alunos trouxessem um objeto qualquer (livro, cd de música, filme, pintura etc.), resultado da produção intelectual em uma área de conhecimento. Para a elaboração da versão inicial, o professor propôs aos estudantes as seguintes questôes: (1) Diga algo mais geral sobre o objeto/produto; (2) Quem é o autor/ artista/ produtor do objeto? (3) O que é/ foi marcante nesse objeto/produto? (4) Quem se interessaria por isso? (5) Como foi lançado esse produto? (6) Como esse produto él está organizado? (7) Quantas partes o constituem? (8) Do que 
trata cada parte? (9) Avalie se o modo de organização desse produto/objeto está bom/ruim, positivo/ negativo? (10) Escolha uma das partes para analisar com um pouco mais de detalhes; (11) Você recomendaria o produto? (12) Por quê? A quem?

Após a escrita inicial dessa resenha, o professor solicitou aos alunos que "passassem a limpo", buscando manter o texto original, resultando na versão final do texto 1 .

Para a elaboração do texto 2 (versões inicial e final), antes da escrita propriamente dita, os alunos tiveram aula teórica sobre o gênero acadêmico resenha, na qual foram destacados os movimentos retóricos desse gênero com base nos postulados de Swales (1984; 1990). A partir dessas orientações, os alunos produziram a primeira versão do texto 2 que foi entregue para avaliação do professor. Após as correções do professor, os universitários foram orientados a reescrever o texto gerando a segunda versão.

Assim, tendo em vista que nosso objetivo é analisar as mudanças efetuadas em textos reescritos por graduandos do segundo semestre do curso de Letras, verificando se tais mudanças se relacionam aos movimentos retóricos característicos do gênero resenha, passamos à análise e discussão dos dados.

\section{Análise dos dados e discussão dos resultados}

Diante da questão proposta neste estudo acerca da relação entre as mudanças realizadas pelos sujeitos na reescrita da resenha e os movimentos retóricos desse gênero, apresentamos, primeiro, os quantitativos acompanhados, respectivamente, dos percentuais correspondentes a cada operação realizada pelos sujeitos nos textos. Esclarecemos, entretanto, que os dados apresentados refletem mais uma exposição do processo vivenciado pelos sujeitos na revisão e reescrita dos textos. Outrossim, salientamos que a interpretação virá na seção posterior, quando as operações linguísticas de adição, substituição, supressão e deslocamento serão relacionadas aos movimentos retóricos do gênero resenha e ao modo como os estudantes realizam esses movimentos nos textos que (re)escrevem (ver seção 5.1).

O quadro 2 a seguir mostra as operações efetuadas pelo sujeito $A(S A)$ nos textos 1 e 2 : 
QUADRO 2

Total de operaçôes efetuadas pelo Sujeito A (SA)

\begin{tabular}{|llllll|}
\hline \multirow{2}{*}{ TEXTOS ANALISADOS } & \multicolumn{2}{l|}{ OPERAÇÕES EFETUADAS } & & \\
& Adição & Substituição & Supressão & Deslocamento & TOTAL \\
\hline \multirow{2}{*}{ TEXTO 1 } & 11 & 11 & 03 & 01 & 26 \\
& $42,30 \%$ & $42,30 \%$ & $11,53 \%$ & $3,84 \%$ & 25 \\
\hline \multirow{2}{*}{ TEXTO 2 } & 11 & 08 & 05 & 01 & 51 \\
& $44 \%$ & $32 \%$ & $20 \%$ & $4 \%$ & \\
\hline TOTAL & 22 & 19 & 08 & 02 & $3,92 \%$ \\
\hline
\end{tabular}

O quadro 2 apresenta o total de mudanças realizadas por SA na reescrita dos dois textos, com seus respectivos percentuais. Esclarecemos que para a escrita, revisão e reescrita do texto 2 as orientaçôes foram ampliadas, de forma que os alunos tiveram acesso, inclusive, ao modelo com a descrição esquemática das estratégias retóricas usadas no gênero resenha (MOTTAROTH, 1995), o que parece não ter mudado o número de alterações, haja vista que não percebemos mudanças acentuadas nos percentuais dos dois textos, exceto uma diferença aproximada de $10 \%$ a menos na operação de substituição e $8 \%$ a mais na operação de supressão, quando comparamos os textos 1 e 2 .

Abaixo, disponibilizamos o quadro 3 relativo às mudanças efetivadas pelo Sujeito B:

QUADRO 3

Total de mudanças efetuadas pelo Sujeito B (SB)

\begin{tabular}{|c|c|c|c|c|c|}
\hline \multirow[b]{2}{*}{ TEXTOS ANALISADOS } & \multicolumn{4}{|c|}{ OPERAÇŌES EFETUADAS } & \multirow[b]{2}{*}{ TOTAL } \\
\hline & Adição & Substituição & Supressão & Deslocamento & \\
\hline \multirow{2}{*}{ TEXTO 1} & 17 & 14 & 13 & 00 & \multirow[t]{2}{*}{44} \\
\hline & $38,63 \%$ & $31,81 \%$ & $29,54 \%$ & $0 \%$ & \\
\hline TEXTO 2 & $\begin{array}{c}11 \\
32,35 \%\end{array}$ & $\begin{array}{c}15 \\
44,11 \%\end{array}$ & $\begin{array}{c}05 \\
14,70 \%\end{array}$ & $\begin{array}{c}03 \\
8,82 \%\end{array}$ & 34 \\
\hline \multirow[t]{2}{*}{ TOTAL } & 28 & 29 & 18 & 03 & 78 \\
\hline & $35,89 \%$ & $37,17 \%$ & $23,07 \%$ & $3,84 \%$ & \\
\hline
\end{tabular}

O quadro 3 revela que pequenas discrepâncias entre os dados podem ser observadas, como, por exemplo, um percentual maior de elementos 
adicionados por SA, enquanto SB faz mais substituições. É bem verdade que esses números não se apresentam como dados substanciais, já que as operações de adição e substituição de SA representam, respectivamente, $43,13 \%$ e $37,25 \%$ do total de mudanças efetuadas, enquanto as mesmas operaçôes realizadas por SB equivalem, respectivamente, a 35,89\% e $37,17 \%$.

A análise do corpus mostra que, entre os tipos de operação revisional, os estudantes optaram por mobilizar as operações de adição e substituição, ratificando estudos anteriores (SOARES, 2003), que apontam a substituição como estratégia mais utilizada na revisão/reescrita do texto e ampliando tais estudos com o percentual de operações de adição, enquanto a operação de deslocamento foi a que apareceu com menor número, conforme observamos nos quadros 3 e 4, corroborando os estudos de Fabre-Cols (2002), que desenvolveu pesquisas com alunos de escola primária.

De forma geral, um primeiro contato com os textos produzidos inicialmente pelos alunos mostra-nos que, mesmo realizando a tarefa do "passar a limpo", os sujeitos fazem alterações em seus textos, seja simplesmente para alterar aspectos formais, seja para alterar aspectos referentes aos movimentos retóricos típicos do gênero resenha. Ressaltamos que embora os sujeitos sejam iniciantes na produção do gênero resenha acadêmica, podemos perceber, mesmo que timidamente, traços dos movimentos retóricos desse gênero de acordo com os pressupostos de Swales (1990). Acreditamos que essas recorrências devem-se ao fato de que, como argumenta Bezerra (2009), o gênero resenha transita tanto no ambiente escolar como no meio acadêmico.

A seguir, apresentamos trechos que revelam mudanças entre as duas versões dos textos (escritos/reescritos), bem como algumas reflexões acerca dessas mudanças.

$\mathrm{Na}$ sequência, disponibilizamos uma alteração realizada por SB. Acreditamos que a substituição efetuada no primeiro parágrafo do texto 1 , na reescrita da versão inicial para a versão final (AMOR / SENTIMENTO), foi realizada no intuito de estabelecer uma equivalência formal/semântica mais ou menos estreita, uma vez que essa substituição realiza-se entre dois termos encontrados em um mesmo paradigma, pois, como afirma FabreCols (2002), a alteração de substituição é por excelência uma relação entre dois termos podendo se encontrar em um mesmo paradigma. Vejamos o exemplar 1 abaixo: 


\begin{tabular}{|c|c|}
\hline Parágrafo 1 (T1 - VI) & Parágrafo 2 (T1 - VF) \\
\hline $\begin{array}{l}\text { O filme Crepúsculo retrata a história de amor entre } \\
\text { uma humana e um vampiro; um amor simples, } \\
\text { incondicional, que nos faz imaginar como seria viver } \\
\text { um amor tão puro incomum como este que enfrenta } \\
\text { a própria essência e supera tudo em nome desse amor. }\end{array}$ & $\begin{array}{l}\text { O filme Crepúsculo retrata a história de amor entre } \\
\text { uma humana e um vampiro; um amor simples, } \\
\text { incondicional, que nos faz imaginar como seria viver } \\
\text { um sentimento incomum, que enfrenta até a própria } \\
\text { essência, e supera tudo em nome desse amor. }\end{array}$ \\
\hline
\end{tabular}

Exemplar 1 - Sujeito B

Além disso, assim como Fabre-Cols (2002) verificou em sua análise, também nós identificamos em nosso corpus dois tipos de substituição, conforme ilustramos por meio dos exemplares 2 e 3, subsequentemente.

(i) A substituição que modifica o plano da expressão sem afetar, em princípio, aquele do conteúdo a comunicar:

\begin{tabular}{|c|c|}
\hline \multicolumn{1}{|c|}{ Parágrafo 1 (T1 - VI) } & \multicolumn{1}{|c|}{ Parágrafo 2 (T1 - VF) } \\
\hline $\begin{array}{l}\text { É um filme emocionante sobre a história pessoal de } \\
\text { um garoto em busca do conserto de um homem } \\
\text { mecânico, mas também mostra o início do cinema. }\end{array}$ & $\begin{array}{l}\text { A invenção de Hugo Cabret é uma adaptação } \\
\text { emocionante do livro de Brian Selznick, que conta } \\
\text { a história de um menino órfão de 12 anos que vive } \\
\text { escondido em uma estação de trem de Paris e, sozinho, } \\
\text { cuida dos enormes relógios do lugar em busca do } \\
\text { conserto de um homem mecânico, mas também } \\
\text { mostra o início do cinema. }\end{array}$ \\
\hline
\end{tabular}

Exemplar 2 - Sujeito A

(ii) A modificação que altera ao mesmo tempo a expressão e o conteúdo:

\begin{tabular}{|c|c|}
\hline Parágrafo 2 (T2 - VI) & Parágrafo 2 (T2 - VF) \\
\hline $\begin{array}{l}\text { Essa última, por sua vez, em sua vida escolar não era } \\
\text { contextualizada com a leitura de seu mundo, do } \\
\text { quintal de sua casa, onde a terra era sua lousa e os } \\
\text { gravetos os seus lápis. Afirma também que para haver } \\
\text { uma melhor compreensão do que se lê é necessário } \\
\text { que haja uma percepção entre texto e contexto. A } \\
\text { contextualização é um tópico sempre presente em } \\
\text { suas teses. }\end{array}$ & $\begin{array}{l}\text { Essa última, por sua vez, em sua vida escolar não era } \\
\text { relacionada com a leitura de seu mundo particular, } \\
\text { onde no quintal de sua casa a terra assumia o papel } \\
\text { de lousa e os gravetos de lápis. Afirma também que } \\
\text { para haver um melhor entendimento do que se lê } \\
\text { é necessário que haja uma percepção entre texto e } \\
\text { contexto. }\end{array}$ \\
\hline
\end{tabular}

Exemplar 3 - Sujeito A 
Conforme mencionamos anteriormente, em algumas mudanças observadas nos textos reescritos, podemos perceber, ainda que timidamente, que tais mudanças apontam para alguns dos movimentos retóricos do gênero resenha (SWALES, 1990). As práticas de (re)escrita no ensino do gênero resenha e a orientação acerca da descrição esquemática das estratégias retóricas, usadas nesse gênero, parecem contribuir para estabelecer relações entre as operações realizadas na reescrita e os movimentos retóricos, assunto da próxima seção.

\subsection{Relações entre as operações efetuadas na reescrita e os movimentos retóricos}

Segundo Motta-Roth e Hendges (2010) a estrutura retórica da resenha compõe-se, basicamente, de quatro etapas nas quais os sujeitos realizam as ações de 1- apresentar, 2- descrever, 3-avaliar e 4- (não) recomendar o objeto resenhado. Dessa forma, verificamos que, em certas ocorrências, as operaçōes efetuadas, nesse caso, em maior número as de acréscimo, são utilizadas, também, com o propósito de introduzir elementos que remetem aos movimentos retóricos típicos do gênero resenha acadêmica, como podemos observar no exemplar 4, abaixo.

\begin{tabular}{|c|c|}
\hline Parágrafo 2 (T1 - VI) & Parágrafo $2(\mathrm{~T} 1$ - VF) \\
\hline $\begin{array}{l}\text { A saga Crepúsculo é uma série de livros escritos } \\
\text { pela autora Stephenie Meyer, tornando-se suecesso } \\
\text { mundial e sendo adaptado para o cinema e no filme de } \\
\text { estreia só aqui no Brasil mais de } 2.000 .000 \text { de pessoas } \\
\text { já assitiram nos cinemas. }\end{array}$ & $\begin{array}{l}\text { A saga Crepúsculo é uma série de livros escritos por } \\
\text { Stephenie Meyer, lido por mais de } 17 \text { milhões } \\
\text { de pessoas, tornando-se um fenômeno mundial. } \\
\text { Baseado no primeiro livro da saga, em } 2008 \text { foi } \\
\text { lançado o primeiro filme da série homônima } \\
\text { dirigido por Catherine Hardwicke, estrelando os } \\
\text { papeis principais: Kristen Stewart como Isabella } \\
\text { Swan, e Robert Pattinson como Edward Cullen. } \\
\text { No Brasil mais de } 2.000 .000 \text { de pessoas já o assistiram, } \\
\text { somente nos cinemas. }\end{array}$ \\
\hline
\end{tabular}

Exemplar 4 - Sujeito B

Na reescrita do texto 1 , o sujeito, ao ampliar o parágrafo na versão final, utiliza-se da operação de acréscimo/adição para restaurar um componente indispensável que foi omitido em um estado anterior (versão inicial). Assim, esse sujeito avança na APRESENTAÇÃO (movimento retórico da resenha 
acadêmica) da série Crepúsculo, somando informações mais gerais sobre a obra, o autor, o lançamento, o público leitor etc.

Outro exemplo de mudança relacionada aos movimentos retóricos verificamos na reescrita do texto 2 pelo sujeito $\mathrm{A}$, como demonstramos no exemplar 5, subsequentemente:

\begin{tabular}{|c|c|}
\hline Parágrafo 2 (T2 - VI) & Parágrafo $2(\mathrm{~T} 2-\mathrm{VF})$ \\
\hline $\begin{array}{l}\text { A leitura do livro proporciona uma abertura de } \\
\text { horizontes quando se trata de educação. Percebemos } \\
\text { a real necessidade de inserirmos elementos dos } \\
\text { aprendizes para o mundo da palavra escrita, de forma } \\
\text { que possamos transformá-lo de maneira consciente. } \\
\text { Linguagem e realidade não devem ser dissociadas. }\end{array}$ & $\begin{array}{l}\text { A leitura do livro é recomendada para quem } \\
\text { vai enveredar pelo campo da docência, pois } \\
\text { proporciona uma abertura de horizontes quando } \\
\text { se trata de ensino, apesar do forte apelo político } \\
\text { presente. Percebemos a real necessidade de inserimos } \\
\text { elementos dos aprendizes para o mundo da palavra } \\
\text { escrita, de forma que possamos transformá-lo de } \\
\text { maneira consciente, onde linguagem e realidade não } \\
\text { devem ser dissociadas. }\end{array}$ \\
\hline
\end{tabular}

Exemplar 5 - Sujeito A

Como vemos no exemplar acima, o estudante, ao adicionar informações na reescrita do seu texto demonstra especial atenção com o movimento retórico (NÃO) RECOMENDAR, deixando claro ao leitor a importância da obra para futuros docentes. Mais uma vez, os dados nos autorizam a retomar a tese de Fabre-Cols (2002) segundo a qual as marcas de reescrita deixadas no texto pelos escreventes não se restringem apenas aos saberes linguísticos que eles detêm, mas sinalizam para importantes pistas sobre a compreensão que eles constroem acerca do gênero que estão praticando.

Nessa mesma direção, também verificamos a preocupação do sujeito $\mathrm{B}$, texto 2 , em introduzir ações referentes ao movimento retórico DESCREVER. Vejamos o exemplar 6 a seguir: 


\begin{tabular}{|c|c|}
\hline Parágrafo 2 (T2 - VI) & Parágrafo 2 (T2 - VF) \\
\hline $\begin{array}{l}\text { Certo dia Gregor acorda transformado em um } \\
\text { inseto gigante e monstruoso- que não consegue } \\
\text { levantar de sua cama, impedindo-o de ir ao trabalho. } \\
\text { Inicialmente, psicologicamente, Gregor não se dá } \\
\text { conta da situação que se encontra, e tenta ir trabalhar, } \\
\text { mas como? No estado assustador que se encontrava! } \\
\text { A partir desse momento começa o drama de Gregor, } \\
\text { pois seus pais querem que ele saia de qualquer forma } \\
\text { do quarto, mas ele tem receio do que seus pais irão } \\
\text { fazer ao vê-lo na forma de inseto. }\end{array}$ & $\begin{array}{l}\text { Em A Metamorfose há predominância marcante } \\
\text { de Realismo fantástico, possuindo três capítulos } \\
\text { narrados em terceira pessoa contando-nos a história } \\
\text { de Gregor Samsa, um caixeiro viajante escravo do } \\
\text { trabalho para tentar manter os padrões de vida da sua } \\
\text { família. No primeiro capítulo do livro, Gregor acorda } \\
\text { transformado em um inseto gigante e monstruoso que } \\
\text { não consegue levantar de sua cama, impedindo-o de ir } \\
\text { ao trabalho. Inicialmente, psicologicamente, Gregor } \\
\text { não se dá conta da situação em que se encontra, } \\
\text { e tenta ir ao trabalhar, mas como? No estado que } \\
\text { se encontrava? A partir desse momento, começa o } \\
\text { drama de Gregor, pois seus pais querem que ele saia } \\
\text { de qualquer forma do quarto para ir trabalhar, mas } \\
\text { ele tem receio do que eles irão fazer ao vê-lo a forma } \\
\text { de inseto. }\end{array}$ \\
\hline
\end{tabular}

Exemplar 6 - Sujeito B

Como podemos perceber, ao longo do texto, o movimento retórico relativo à descrição da obra se deixa entrever por meio das operaçôes de adição, substituição e deslocamento. Reiteramos que, ao usar essas operações, os sujeitos não revelam apenas conhecimentos linguísticos relacionados à reescrita, mas apontam para um esforço de dar conta do movimento retórico da descrição da resenha. Em função disso, o sujeito busca detalhar a obra, indicando a organização do livro, as partes que o constituem e o assunto abordado. Além disso, a inserção de expressôes como "No primeiro capitulo do livro" evidencia a necessidade que sente o sujeito de situar o leitor de sua resenha, caracterizando o texto como pertencente ao gênero resenha acadêmica, a partir dos pressupostos teóricos discutidos em sala de aula.

Já no exemplo do Sujeito A, texto 1, as mudanças operacionalizadas expõem, entre outros aspectos, a relevância da reescrita, tendo em vista o grau de informatividade que o sujeito deseja imprimir ao texto, como observamos na ampliação do trecho da versão final. Atentemos para o exemplar 7, na sequência: 


\begin{tabular}{|l|l|}
\hline \multicolumn{1}{|c|}{ Parágrafo 1 (T1-VI) } & \multicolumn{1}{|c|}{ Parágrafo 1 (T1-VF) } \\
\hline $\begin{array}{l}\text { O modo como Takeda compôs o livro surpreende, } \\
\text { apesar de tratar de assuntos tão comuns. }\end{array}$ & $\begin{array}{l}\text { O modo como Takeda compôs o Clube dos Coraçōes } \\
\text { Solitários surpreende por sua simplicidade de escrita e } \\
\text { pelos temas cotidianos, como as incertezas sobre o } \\
\text { futuro, estabilidade profissional, amadurecimento } \\
\text { e perdas. Muitos críticos costumam compará-lo a } \\
\text { escritores como Nick Hornby (Alta Fidelidade) } \\
\text { ou J. D. Salinger (O Apanhador no Campo de } \\
\text { Centeio) por tratarem de assuntos semelhantes } \\
\text { em suas obras: o desespero e a intensidade comum } \\
\text { dos adolescentes, apesar de Takeda afirmar que sua } \\
\text { maior influência sejam as músicas pops e o escritor } \\
\text { Douglas Coupland, autor da novela Generation X: } \\
\text { Tales for an Accelerated Culture, de 1991. }\end{array}$ \\
\hline
\end{tabular}

Exemplar 7 - Sujeito A

Salientamos que, ao usar as operações de adição e substituição em destaque no excerto acima, o escrevente investe no movimento retórico da avaliação da obra, pondo em destaque aspectos do livro que julga relevantes, na tentativa de persuadir o leitor acerca da opinião crítica que desenvolve em sua resenha.

De forma geral, observamos que a atividade de revisão/reescrita dos textos permitiu aos sujeitos refletir sobre os escritos e efetuar mudanças, sejam essas relacionadas aos movimentos retóricos do gênero resenha, ou a aspectos da superfície dos textos. Entretanto, cabe aqui assinalar a relevância da metodologia adotada pelo professor na perspectiva do processo de escrita do gênero resenha.

\section{Considerações finais}

A produção de textos na universidade e/ou na escola pode ser mais significativa se for associada a situações reais de escrita, isto é, a práticas de letramentos bem sucedidas. Além disso, escrever leva tempo e os estudantes precisam vivenciar um processo através do qual eles percebam que nenhum texto fica pronto na primeira versão. Há rotinas próprias de cada gênero que devem ser observadas na hora da produção processual do texto. Assim, o objetivo deste trabalho foi associar a proposta metodológica para análise de gêneros de Swales $(1984,1990)$ com as estratégias linguísticas de revisão e reescrita de texto, propostas por Fabre-Cols (2002).

Os sujeitos participantes de nosso estudo estavam expostos a esses modelos de escrita e reescrita, na situação didática em que aprendiam as 
sutilezas da composição do gênero resenha e, em função disso, buscamos analisar as mudanças efetuadas em textos reescritos por graduandos. A conclusão a que chegamos nos permite sugerir que o ensino de gêneros textuais acadêmicos pode ser produtivo se for realizado na perspectiva processual, ou seja, criando situações didáticas por meio das quais o estudante possa escrever e reescrever, várias vezes, o seu texto.

A reescrita, portanto, deve ser uma oportunidade para refletir sobre as escolhas linguísticas e textuais que tracejam a redação. Nesse sentido, à luz da análise dos dados e da nossa experiência didática de ensino de gêneros acadêmicos, na disciplina LPTA do curso de Letras da UFC, é possível afirmar que o ensino da produção textual, articulado, principalmente, a partir de modelos (SWALES, 1990), possibilita reflexōes entre o estado atual do texto escrito em uma primeira versão e as lacunas que precisam ser preenchidas, pois, as operaçôes linguísticas feitas pelos alunos no exercício de reescrita de seus textos se relacionam intimamente aos movimentos retóricos característicos dos gêneros acadêmicos trabalhados, como a resenha aqui analisada.

Finalmente, podemos atestar que os estudantes compartilharam de uma experiência de aprendizagem da escrita, certamente, mais proveitosa do ponto de vista da apropriação dos letramentos acadêmicos, haja vista a perspectiva processual de escrita e reescrita vivenciada por todos.

\section{Referências}

ANTUNES, Irandé. Aula de português: encontro e interação. São Paulo: Parábola Editorial, 2003.

ARAÚJO, Antônia Dilamar. Lexical signalling: a study of unspecific-nouns in book reviews. 1996. Tese (Doutorado em Linguística Aplicada) - Universidade Federal de Santa Catarina, Florianópolis.

ARAÚJO, Júlio; SANTOS, Leonel. A ferramenta digital máquina de quadrinhos em uma experiência didática com letramento visual. In: Ribeiro, Ana Elisa; Novais, Ana Elisa. (Org.). Letramento digital em 15 cliques. Belo Horizonte: RHJ, 2012, v.1, p.45-57.

ARAÚJO, Júlio. Os gêneros digitais e os desafios de alfabetizar letrando. Trabalhos em Linguistica Aplicada, v. 46 (1), p.79-92, 2007.

BARROS, Marcilene Gaspar; SOARES, Maria Elias. Re) Escrita da seção justificativa do projeto de pesquisa por escritores iniciantes. Cadernos do IL, Porto Alegre, no. 46, p.107-128, junho de 2013. 
BEZERRA, Benedito Gomes. A resenha acadêmica em uso por autores proficientes e iniciantes. In: BIASI-RODRIGUES, B.; ARAÚJO, J. C.; SOUSA, S. C. T. (Org.). Gêneros textuais e comunidades discursivas: um diálogo com John Swales. Belo Horizonte: Autêntica Editora, 2009, p. 95-115.

BHATIA, Vijay K. Worlds of Written Discourse: A Genre-Based View. London: Continuum International, 2004.

BIASI-RODRIGUES, Bernadete. A diversidade dos gêneros textuais no ensino: um novo modismo? Perspectiva. Florianópolis, v.20, n.01, p.49-64, jan./jun. 2002. BIASI-RODRIGUES, Bernadete. Estratégias de condução de informaçōes em resumos de dissertaçôes. 1998. Tese (Doutorado em Linguística) - Universidade Federal de Santa Catarina, Florianópolis.

BONINI, Adair. Metodologias do ensino de produção textual: a perspectiva da enunciação e o papel da Psicolinguística. Perspectiva. Florianópolis, v.20, n.01, p.23-47, jan./jun. 2002.

BRASIL. Secretaria de Educação Fundamental. Parâmetros Curriculares Nacionais: Língua Portuguesa / Secretaria de Educação Fundamental, Ministério da Educação e do Desporto, 1997.

CARVALHO, Guido de O. Revisão colaborativa de textos escritos em língua inglesa por alunos iniciantes do curso de Letras. 2002. 168f. Dissertação (Mestrado em Letras e Linguística). Faculdade de Letras da Universidade Federal de Goiânia - UFG, Goiânia, 2002.

DIEB, Messias. A leitura na sala de aula. In. COSCARELLI, Carla. V. (Org.). Leituras sobre a leitura: passos e espaços na sala de aula. Belo Horizonte: Veredas, 2013, p. 36-59.

DOLZ et al. Sequências didáticas para o oral e escrita: apresentação de um procedimento. In: R. ROJO e G.S. CORDEIRO (Org. e Trad.), Gêneros orais e escritos na escola. Campinas: Mercado de Letras, 2004. p.95-128.

FABRE-COLS, Claudine. Réécrire à l'école et au collège: de l'analyse de brouillons à l'écriture accompagnée. France: ESF Éditeur, 2002.

FLOWER, Linda; HAYES, John. A Cognitive Process Theory of Writing. College Composition and Communication. v.32, n.4, p.365-387, 1981.

GONÇALVES, Maria Dulce M. Processos psicológicos na revisão da composiz̧ãa escrita: contributos para o desenvolvimento de estratégias de aprendizagem. 1992. $174 \mathrm{f}$. Dissertação (Mestrado em Ciências da Educação). Universidade de Lisboa, Lisboa, 1992. HAYES, John. What Triggers Revision? In.: ALLAL, Linda; CHANQUOI, Lucile; LARGY, Pierre (Ed.). Revision: Cognitive and Instructional Processes. Norwell, Massuchusetts: Kluwer Academic Publishers, 2004. 
HAYES, John. New Directions in Writing Theory. In.: MACARTHUR, C. A. GRAHAM, S. FITZGERALD, J. (Org.). Handbook of Writing Research. Guilford Publications, 2006. Disponível em: http://digis.ewha.ac.kr/data/test/56.New_ Directions_in_Writing_Theory__John_R._Hayes.pdf. Acesso em: 18/10/2012. HAYES et al. Cognitive Processes in Revision. In. ROSENBERG, Sheldon (Org.). Advances in Applied Psycholinguistics: reading, writing and language learning. v. 2. Cambridge University Press, 1987.

HAYES, John.; FLOWER, Linda. Identifying the Organization of Writing Process. In: GREGG, L. W.; STEINBERG, E. R. (Org.). Cognitive processes in writing. New Jersey: Lawrence Erlbaum, 1980.

MARCUSCHI, L. A. Apresentação. In: BAZERMAN, C. Gêneros Textuais, Tipificação e Interação. São Paulo: Cortez, 2005. p.9-13.

MOTTA-ROTH, Desirée. Rhetorical Features and Disciplinary Cultures: a genrebased study of academic book reviews in linguistics, chemistry and economics. 1995. Tese (Doutorado em Linguística Aplicada) - Universidade Federal de Santa Catarina, Florianópolis.

MOTTA-ROTH, Desirée; HENDGES, Graciela Rabuske. Produção textual na universidade. São Paulo: Parábola Editorial, 2010.

SANTOS, Carmi Ferraz. O professor e a escrita: entre práticas e representações. Tese (Doutorado em Linguística Aplicada) Instituto de Estudos Linguísticos da Universidade Estadual de Campinas, Campinas, 2004.

SCHNEUWLY, B. e DOLZ, J. Gêneros escolares: das práticas de linguagem aos objetos de ensino, 1995 (mimeo).

SERAFINI, Maria Teresa. Como escrever textos. 8.ed. São Paulo: Globo, 1992.

SNYDER, Ilana. The Literacy Wars: why teaching children to read and write is a battleground in Australia. Sidney: Allen \& Unwin, 2008.

SOARES, Maria Vilani. A tarefa de reformulação de texto. 2003. Dissertação (Mestrado em Linguística). Universidade Federal do Ceará, Fortaleza, 2003.

SWALES, John M. Genre Analysis: English in academic and research settings. Cambridge University Press, 1990.

SWALES, John M. Research Into the Structure of Introductions to Journal Articles and its Application to the Teaching of Academic Writing. In: WILLIAMS, R.; SWALES, J; KIRKMAN, J. Common Ground: shared interests in ESP and communication studies. ELT Documents 117, 1984.

Data de submissão: 20/02/2014. Data de aprovação: 02/07/2014. 